\title{
O DIREITO À EDUCAÇÃO DE JOVENS EM CUMPRIMENTO DE MEDIDAS SOCIOEDUCATIVAS: uma reflexão a partir dos planos estaduais de educação no Brasil
}

\author{
The right to youth education in compliance with social educational measures: a reflection from state \\ education plans in Brazil
}

Le droit à l'éducation des jeunes soumis à des mesures socio-éducatives: une réflexion issue des plans nationaux d'éducation au Brésil

Livia Silva de Souza ${ }^{1}$

Universidade Federal de Brasília

Andreia Lacé ${ }^{2}$

Universidade Federal de Brasília

Daniela Gomes ${ }^{3}$

Secretaria de Estado de Educação do Distrito Federal

Resumo: O presente artigo tem por objetivo descrever e identificar como a política educacional destinada aos jovens em cumprimento de medidas socioeducativas está consignada nas metas e estratégias do Plano Nacional de Educação (2014-2014) e dos Planos Estaduais de Educação das 27 unidades federativas. A pesquisa exploratória, apoiada em fontes primárias, possuiu uma abordagem qualitativa e revelou, entre outros aspectos, que a socioeducação aparece em algumas estratégias vinculada ao sistema prisional e a jovens em situação de rua. Analisamos que a positivação do direito à educação para jovens em cumprimento de medida socioeducativa é um avanço, mas existem fragilidades no que tange ao planejamento e à execução de políticas de escolarização.

Palavras-chave: Socioeducação. Plano Estadual de Educação. Direito à educação.

\begin{abstract}
This article aims to describe and identify how the educational policy aimed at young people in compliance with socio-educational measures is enshrined in the goals and strategies of the National Education Plan and the State Education Plans of the 27 federative units. Exploratory research based on primary sources has a qualitative approach and revealed, among other things, that socio-education appears in some strategies linked to the prison system and homeless child situation. We analyze, that the affirmation of the right to education for young people in compliance with socio-educational measures is getting improvements, but there are weaknesses regarding the planning and implementation of schooling policies.
\end{abstract}

\footnotetext{
${ }^{1}$ Doutoranda em Educação. Universidade Federal de Brasília (UnB). E-mail: livia.ssouza12@gmail.com. ORCID: https:// orcid.org/0000-0001-9491-6156. Lattes: http://lattes.cnpq.br/5913932482711566.

${ }^{2}$ Doutora em Educação. Universidade Federal de Brasília (UnB). E-mail: andreia.mello.lace@gmail.com. ORCID: https:// orcid.org/0000-0002-3549-2696.

${ }^{3}$ Especialista em Educação Especial no Sistema Penitenciário. Secretaria de Estado de Educação do Distrito Federal. E-mail: gndaniela02@gmail.com. ORCID: https://orcid.org/0000-0001-5055-8211.
} 
Keywords: Socioeducation. State Education Plan. Right to education.

Résumé: Cet article vise à décrire et à identifier comment la politique éducative destinée aux jeunes qui sont soumis à des mesures socio-éducatives est insérée dans les objectifs et les stratégies du Plan National d'Éducation et des Plans d'État d'Éducation des 27 unités fédératives. La recherche exploratoire basée sur des sources primaires a une approche qualitative et a révélé, entre autres, que la socio-éducation apparaît dans certaines stratégies liées au système pénitentiaire et aux jeunes sans abri. Nous analysons, que la positivisation du droit à l'éducation des jeunes qui sont soumis à des mesures socio-éducatives constitue un progrès, mais que la planification et la mise en oeuvre des politiques en matière d'éducation présentent des faiblesses.

Mots-clés: Socio-éducation. Plan National d'Éducation. Droit à l'éducation.

Recebido em: 29 de agosto de 2019 Aceito em: 05 dezembro de 2019

\section{1- Introdução}

Elaborar, debater e analisar políticas públicas de atendimento à juventude em cumprimento de medida socioeducativa são um desafio complexo e permanente para todos os profissionais e pesquisadores envolvidos com jovens que cometem atos infracionais ${ }^{4}$ A experiência com a implementação da política pública de escolarização no Sistema Socioeducativo do Distrito Federal ${ }^{5}$ o acompanhamento da gestão pedagógica dos Núcleos de Ensino das Unidades de Internação Socioeducativas ${ }^{6}$ em curso de extensão com jovens em cumprimento de medidas socioeducativas ${ }^{7}$ ampliou as reflexões tecidas no presente artigo. Nesse contexto, temos por objetivo descrever e identificar como a política educacional destinada aos jovens em cumprimento de medidas socioeducativas está consignada nas metas e estratégias do Plano Nacional de Educação (BRASIL, 2014) e nos Planos Estaduais de Educação das 27 unidades federativas. Pretendemos, ainda, verificar se após a aprovação da

\footnotetext{
4. Atos Infracionais - São as condutas descritas como crime ou contravenção penal cometido por crianças ou adolescentes (Artigo 103, ECA). São atos infracionais mais comuns: roubo; tráfico de drogas; lesão corporal; homicídio; porte de armas; furto; desacato, entre outros.

${ }^{5}$ O Sistema Socioeducativo do Distrito Federal tem como órgão gestor a Secretaria de Estado de Justiça e Cidadania do DF, é composto por 1(uma) Unidade de Atendimento Inicial - NAI, 15 (quinze) Unidades de Atendimento em Meio Aberto - UAMA, 6 (seis) Unidades de Atendimento em Semiliberdade - USL e 7 (sete) Unidades de Internação Socioeducativas

${ }^{6}$ Denominamos por Núcleos de Ensino, as escolas dentro das Unidades de Internação Socioeducativas cuja gestão é de responsabilidade da Secretaria de Estado de Educação do Distrito Federal (SEEDF).

${ }^{7}$ Medidas Socioeducativas - São medidas de caráter educativo aplicadas às crianças ou adolescentes que praticaram atos infracionais (Artigo 112, ECA). São Medidas Socioeducativas: advertência; obrigação de reparar o dano; prestação de serviço à comunidade; liberdade assistida; semiliberdade e internação em estabelecimento educacional.
} 
Lei 12.594/2012 (BRASIL, 2012), que institui o Sistema Nacional de Atendimento Socioeducativo (SINASE), os planejamentos estaduais e distrital incorporaram a garantia do direito à educação de jovens e adolescentes que cometeram ato infracional.

A pesquisa exploratória apoiada em fontes primárias possuiu uma abordagem qualitativa. No processo de busca nos Planos Estaduais de Educação, utilizamos de indexadores específicos (socioeducação, sistema socioeducativo, privação de liberdade, liberdade, medida socioeducativa). Os retornos da pesquisa foram sistematizados em quadros analíticos e divididos pelas cinco regiões brasileiras de modo a evidenciar como os Planos Estaduais de Educação consignaram a socioeducação em seus documentos.

Pensar o debate acerca do direito à educação na socioeducação implica em considerar que a maioria dos jovens incluídos nesse sistema têm direitos violados desde a primeira infância. Dados do Instituto de Pesquisas Econômicas Aplicadas (IPEA), em nota técnica produzida sobre o tema ${ }^{8}$, demonstram que $90 \%$ dos jovens que cometem ato infracional são do sexo masculino; $76 \%$ têm idade entre 16 e 18 anos; mais de 60\% são negros; $51 \%$ não frequentam a escola; $49 \%$ não trabalham; $66 \%$ vivem em famílias consideradas extremamente pobres, sendo que $85,6 \%$ são usuários de drogas.

No âmbito do atendimento socioeducativo, as pesquisas têm se ampliado nos últimos anos e apresentam diferentes enfoques, sendo as Ciências Humanas e Sociais as áreas que mais têm se dedicado ao tema. No entanto, a carência de estudos científicos relacionados ao planejamento educacional e socioeducação potencializou nosso interesse pelo assunto. São ainda bem recentes, em nosso país, pesquisas voltadas à análise de políticas públicas de escolarização no contexto socioeducativo. Sposito (2009) organizou um livro com o estado da arte sobre juventude na pós-graduação brasileira (1999-2006) e constatou que os estudos que abordam a relação dos adolescentes em conflito com a lei com a educação formal trazem como pressuposto o direito à educação e à proteção integral. Os autores mencionados por Sposito (2009) (BRANCALHÃO, 2003; ARONE, 2006; SARAIVA, 2006; PEREIRA, 2006) são unânimes em apontar a debilidade do Estado na garantia efetiva do direito à educação de crianças e adolescentes inseridos no sistema socioeducativo.

Em relação ao direito à educação, importa considerar que o artigo $6^{\circ}$ da Constituição Federal (BRASIL, 1988) consigna a educação como o primeiro dos direitos sociais ${ }^{9}$. Com isso, a educação é imprescindível para o desenvolvimento do ser humano, elemento

${ }^{8} \mathrm{O}$ adolescente em conflito com a lei e o debate sobre a redução da maioridade penal: esclarecimentos necessários (2015).

${ }^{9}$ Art. $6^{\text {o }}$ - São direitos sociais a educação, a saúde, a alimentação, o trabalho, a moradia, o transporte, o lazer, a segurança, a previdência social, a proteção à maternidade e à infância, a assistência aos desamparados, na forma desta Constituição (Artigo com redação dada pela Emenda Constitucional nº 90, de 2015). 
fundamental para a aquisição de outros direitos e para o exercício pleno da cidadania, conforme assevera o artigo 205 da referida Constituição. A educação, neste artigo, é reconhecida como direito de todos e garantida pelo Estado, pela família e pela sociedade, cujas finalidades são o desenvolvimento pleno da pessoa, seu preparo para o exercício da cidadania e sua qualificação para o trabalho (BRASIL, 1988).

A partir do reconhecimento da educação como um direito de todos, apresentar-se-á o percurso dos marcos regulatório do direito à educação dos jovens em cumprimento de medidas socioeducativas.

\section{A garantia do direito à educação nos marcos normativos que orientam e regulam o sistema socioeducativo}

Ao considerar que a luta pela garantia do direito à educação de jovens em cumprimento de medidas socioeducativas situa-se no âmbito dos direitos humanos, destacamos a concepção de Flores (2008), que propõe uma nova perspectiva dos direitos ao enunciar que falar de direitos humanos é falar de processos institucionais e sociais que possibilitem a abertura e a consolidação de espaços de luta pela dignidade humana. Nesse ponto de vista, contesta os direitos humanos como categoria prévia à ação política ou práticas econômicas e reconhece que a luta pela dignidade humana é a consequência da luta pela democracia e pela justiça.

A Constituição Cidadã de 1988 mudou substancialmente a forma de ver e entender o cuidado a ser dispensado às crianças e adolescentes. Vale destacar que o referido artigo foi modificado pela Emenda Constitucional n 65, de 2010, incluindo a categoria "jovem" dentre as prioridades:

Art. 227. É dever da família, da sociedade e do Estado assegurar à criança, ao adolescente e ao jovem, com absoluta prioridade, o direito à vida, à saúde, à alimentação, à educação, ao lazer, à profissionalização, à cultura, à dignidade, ao respeito, à liberdade e à convivência familiar e comunitária, além de colocá-los a salvo de toda forma de negligência, discriminação, exploração, violência, crueldade e opressão (BRASIL, 1988).

O Estatuto da Criança e do Adolescente (ECA) (BRASIL, 1990), ao regulamentar o referido artigo da Constituição Federal, detalha os direitos da criança e do adolescente que cometem ato infracional, entre eles, o direito à escolarização. Especificamente, esse direito é assegurado nos Arts.. 94, 120 e 124, que reconhecem a oferta de escolarização como uma obrigação das unidades de internação, do regime de semiliberdade e como um direito do 
adolescente privado de liberdade.

O ECA (BRASIL, 1990) transformou o tratamento legal dispensado à criança e ao adolescente no que diz respeito ao direito à escolarização de adolescente em conflito com a lei, pois assegurou a garantia deste, entretanto, o ECA foi insuficiente na regulamentação desses direitos, pois não tratou de forma concreta sobre os procedimentos para a execução das medidas, bem como sobre a organização e oferta da escolarização nas instituições socioeducativas.

Para dar efetividade às regras e recomendações do ECA, iniciou-se a partir de 2002 uma série de encontros e debates ${ }^{10}$ sobre a proposta de uma lei de execução das medidas socioeducativas, que se concretizou com a sanção da Lei $\mathrm{n}^{\circ}$ 12.594, em janeiro de 2012. Antes do advento dessa Lei, porém, após 16 anos de vigência do ECA, a Secretaria Especial dos Direitos Humanos da Presidência da República e o Conselho Nacional dos Direitos da Criança e do Adolescente (CONANDA) apresentam, por meio da resolução nº 119/2006, o Sistema Nacional de Atendimento Socioeducativo (SINASE). Essa resolução constituiu-se como política pública destinada à inclusão de adolescente em conflito com a lei correlacionada a diferentes políticas públicas e sociais.

Nesse documento, a escolarização é pautada dentro dos Princípios e Marco Legal do Sistema de Atendimento Socioeducativo que tratam da incompletude institucional e responsabiliza as políticas setoriais no atendimento aos adolescentes, conforme artigo 86 do ECA.

Os programas de execução de atendimento socioeducativo deverão ser
articulados com os demais serviços e programas que visem atender os
direitos dos adolescentes (saúde, defesa jurídica, trabalho,
profissionalização, escolarização etc.). Dessa forma, as políticas sociais
básicas, as políticas de caráter universal, os serviços de assistência social e
de proteção devem estar articulados aos programas de execução das
medidas socioeducativas, visando assegurar aos adolescentes a proteção
integral (BRASIL, 2006, p. 29).

Nesse ponto, é interessante destacar que pela primeira vez é mencionada como a escolarização formal deverá ser ofertada. Por outro lado, ainda há ausência de uma definição clara dos procedimentos pedagógicos e das competências de cada ente federado na execução dessa política. Por exemplo, quando a Resolução de 2006 afirma que entidades ou programas comunitários e rede não governamental podem oferecer escolarização formal (BRASIL, 2006).

\footnotetext{
${ }^{10}$ Em parceria com a Secretaria Especial dos Direitos Humanos, com a Associação Brasileira de Magistrados e Promotores da Infância e Juventude (ABMP) e o Fórum Nacional de Organizações Governamentais de Atendimento a Criança e ao Adolescente (FONACRIAD), o CONANDA desencadeou uma série de encontros estaduais e regionais e um encontro nacional com juízes, promotores de justiça, conselheiros de direito, técnicos e gestores de entidades e/ou programas de atendimento socioeducativo, Fundo das Nações Unidas para a Infância (UNICEF) e o Instituto Latino Americano das Nações Unidas para a Prevenção do Direito e Tratamento do Delinquente (ILANUD/BRASIL).
} 
Embora essa resolução reafirme os princípios e a diretriz do ECA sobre o direito à escolarização de adolescentes em cumprimento de medidas socioeducativas e proponha a inserção dessa política em um sistema integrado ao Sistema de Garantia de Direitos, a oferta de escolarização é apresentada de forma difusa e pontual.

Tal situação se estabiliza no plano legal com a promulgação da Lei ${ }^{\circ}{ }^{\circ}$ 12.594/2012, que institui o SINASE. Nesse contexto, o SINASE é definido como o conjunto ordenado de princípios, regras e critérios que envolvem a execução de medidas socioeducativas, incluindose nele, por adesão, os sistemas estaduais, distrital e municipais, bem como todos os planos, políticas e programas específicos de atendimento a adolescente em conflito com a Lei. O SINASE é coordenado pela União e integrado pelos sistemas estaduais, distrital e municipais responsáveis pela implementação dos seus respectivos programas de atendimento ao adolescente em conflito com a lei. Dentre as competências pertinentes aos Estados, destaca-se a de criar, desenvolver e manter programas para a execução das medidas socioeducativas de semiliberdade e internação; aos Municípios cabem criar e manter programas de atendimento para a execução das medidas socioeducativas em meio aberto e ao Distrito Federal cabem, cumulativamente, as competências dos Estados e dos Municípios (BRASIL, 2012).

Observa-se que esse novo sistema traz o preceito da incompletude institucional, responsabilizando, portanto, cada esfera federativa a exercer e executar o seu papel dentro da medida socioeducativa. Portanto, a oferta de uma educação pública para adolescentes em cumprimento de medida socioeducativa ganha um novo escopo e novos desafios são postos para os setores responsáveis pela educação na esfera estadual, municipal e distrital.

Decorridos quase dois anos da promulgação da Lei do SINASE, em 19 de novembro 2013, foi publicado o Plano Nacional Decenal de Atendimento Socioeducativo (PNDAS), que se constitui numa das principais exigências do SINASE, senão a principal. Nesse documento, uma das diretrizes consiste em garantir o direito à educação para os adolescentes em cumprimento de medidas socioeducativas e egressos, considerando sua condição singular como estudantes e reconhecendo a escolarização como elemento estruturante do sistema socioeducativo.

Outro marco regulatório importante, publicado em 2016, se refere à Resolução do Conselho Nacional de Educação, que define as Diretrizes Nacionais para o atendimento escolar de adolescentes e jovens em cumprimento de medidas socioeducativas. O referido documento determina como princípios do atendimento escolar a prevalência da dimensão educativa sobre o regime disciplinar e a escolarização como estratégia de reinserção social plena, articulada à reconstrução de projetos de vida e à garantia de direitos (BRASIL, 2016).

O estabelecimento das Diretrizes é um marco na política de escolarização no 
atendimento socioeducativo, uma vez que contribui na elaboração de diretrizes pedagógicas e no fortalecimento de ações e estratégias escolares.

Nesse sentido, consideramos relevante identificar se os Planos Estaduais de Educação aprovados, em sua maioria, entre os anos de 2015 e 2016, apresentaram metas e/ou estratégias para a escolarização de jovens em cumprimento de medidas socioeducativas.

\section{0 panorama das metas e/ou estratégias relacionadas à socioeducação nos planos estaduais de educação}

3.1 níveis do planejamento educacional e os planos estaduais de educação

Saviani (2014) e Cury (1998) afirmam que o planejamento educacional é uma ação racional para superar o espontaneísmo da área e organizar a implementação da política educativa, com vistas ao alcance dos fins propostos para a educação: o pleno desenvolvimento da pessoa, o preparo para o exercício da cidadania e a qualificação para o trabalho (BRASIL, 1988).

O planejamento educacional ocorre em diferentes níveis e esferas indo desde a esfera macro (União) até a esfera micro (sala de aula). A Lei de Diretrizes e Bases de 1996 estabelece em seus artigos $9^{\circ}$ ao $11^{\circ}$ os níveis do Planejamento Educacional. Compete à União, em colaboração com os Estados, DF e Municípios, elaborar o Plano Nacional de Educação; assim como compete aos estados, DF e Municípios elaborar e executar políticas e planos educacionais em consonância com as diretrizes e com o Plano Nacional. Os sistemas de ensino têm a incumbência de elaborar e executar sua proposta pedagógica e os docentes devem participar da elaboração da proposta pedagógica da escola e elaborar e cumprir o plano de trabalho. Além disso, o Plano Nacional de Educação (PNE) (BRASIL, 2014), aprovado em 25 de junho de 2014, prevê, no artigo $8^{\circ}$, o prazo de um ano para que Estados, Distrito Federal e Municípios elaborem seus correspondentes planos de educação ou mesmo readéquem os planos que já foram aprovados em lei.

Lacé, Scherre e Souza (2016), ao tratar da historicidade do Plano Nacional de Educação no Brasil, evidenciam as descontinuidades e embates que consolidaram desde a década de 1930, após o lançamento do Manifesto dos Pioneiros da Educação Nova até a aprovação do segundo Plano Nacional de Educação em 2014. Nessa trajetória conflituosa e reveladora do esgarçamento social em torno da matéria educacional, o primeiro Plano Nacional de Educação foi aprovado somente em 2001, no governo do então Presidente do Brasil Fernando Henrique Cardoso (1995- 2003).

Em relação à socioeducação, o Plano Nacional de 2001 apresentou uma única estratégia 
concernente a jovens infratores que previa a implantação em todas as unidades prisionais e nos estabelecimentos que atendessem adolescentes e jovens infratores, programas de Educação de Jovens e Adultos (EJA) de nível fundamental e médio, assim como de formação profissional.

O segundo PNE (BRASIL, 2014) com 20 metas, tal como o Plano de 2001, faz menção à escolarização dos jovens e adolescentes infratores em uma única estratégia, todavia relacionada à meta 7 do Índice de Desenvolvimento da Educação Básica (Ideb). A estratégia prevê a implementação de políticas de inclusão e permanência na escola para adolescentes e jovens que se encontram em regime de liberdade assistida e em situação de rua, assegurando os princípios da lei no-8.069, de 13 de julho de 1990 - Estatuto da Criança e do Adolescente.

Observados esses aspectos relativos aos Planos Nacionais de Educação, no próximo item descreveremos a temática nos PEEs.

3.2 Planos estaduais de educação dos 26 estados e distrito federal

Para efeitos de exposição, apresentaremos os resultados da pesquisa em quadros divididos pelas regiões brasileiras e em seguida a descrição do que foi identificado em relação à socioeducação. Nos comentários, consideraremos os Estados que apresentaram mais de três estratégias em seus PEEs vinculadas ao tema em estudo.

Quadro 1 - Socioeducação nos PEEs dos Estados da Região Norte

\begin{tabular}{|c|c|c|c|}
\hline Estado & $\begin{array}{l}\text { Número da Lei do Plano } \\
\text { Nacional de Educação }\end{array}$ & $\begin{array}{l}\text { Meta sobre a } \\
\text { Socioeducação? }\end{array}$ & $\begin{array}{l}\text { Quantitativo de estratégia e/ou } \\
\text { meta referente à socioeducação }\end{array}$ \\
\hline Acre & $\begin{array}{c}\text { Lei }{ }^{\circ} 2.695 \text {, de } 02 \text { de junho } \\
\text { de } 2015 .\end{array}$ & Não & O2 estratégias \\
\hline Amazonas & $\begin{array}{c}\text { Lei } n^{\circ} 4.183 \text {, de } 26 \text { de junho } \\
\text { de } 2015 .\end{array}$ & Não & 01 estratégia \\
\hline Roraima & $\begin{array}{c}\text { Lei } n^{\circ} 1.008,03 \text { de setembro } \\
\text { de } 2015 .\end{array}$ & Não & O1 estratégia \\
\hline Pará & $\begin{array}{c}\text { Lei } n^{\circ} 8.186,23 \text { de junho de } \\
2015 .\end{array}$ & Não & O3 estratégias \\
\hline Amapá & $\begin{array}{c}\text { Lei } n^{\circ} 1.907,24 \text { de junho de } \\
2015 .\end{array}$ & Não & O1 estratégia \\
\hline Rondônia & $\begin{array}{c}\text { Lei } 1 \mathrm{n}^{\circ} 3.565 \text {, de } 03 \text { de junho } \\
\text { de } 2015 .\end{array}$ & Não & 05 estratégias \\
\hline Tocantins & $\begin{array}{c}\text { Lei }{ }^{\circ} 2.977 \text {, de } 08 \text { de julho } \\
\text { de } 2015 .\end{array}$ & Não & $\begin{array}{c}\text { Meta } 10 \text { (com } 11 \text { estratégias) } \\
+07 \text { estratégias }\end{array}$ \\
\hline
\end{tabular}


Fonte: Elaboração própria (2019).

As regiões Norte e Nordeste possuem o maior número de Estados com estratégias abrangendo a socioeducação, especialmente estratégias ligadas às metas que tratam do ensino fundamental, da educação de jovens e adultos, da EJA integrada à educação profissional e da formação e valorização dos profissionais de educação. Na região Norte, três PEEs dos sete Estados apresentam mais de três estratégias tratando da socioeducação (Pará, Rondônia e Tocantins). Observam-se, no Estado do Pará, estratégias tratando da utilização das tecnologias de informação e comunicação, inclusive com o uso da modalidade a distância nos estabelecimentos socioeducativos. No Estado de Rondônia, por outro lado, evidenciam-se estratégias relacionadas à remuneração diferenciada, a gratificações e à formação específica de professores e profissionais que atuam no sistema. O PEE de Rondônia prevê também a implantação de um Plano Estadual para os adolescentes em medidas socioeducativas.

O Estado do Tocantins, na meta 10, objetiva universalizar a oferta do ensino fundamental e médio, no ensino regular e na EJA, nas unidades socioeducativas. Essa meta, que trata do sistema prisional e da socioeducação, apresenta um conjunto de 11 estratégias abrangendo desde implementar e garantir a permanência na escola, para adolescentes e jovens que se encontram em regime de liberdade assistida e em situação de rua, até a implantação da educação com qualidade socialmente referenciada e em condições de igualdade em relação a outros sistemas. E objetiva assegurar, no sistema socioeducativo e na educação em prisões, parcerias com instituições públicas e privadas que contemplem a educação básica e profissional, garantindo formação humanizada e integral a partir da problematização e contextualização da realidade biopsicossocial dos alunos. 
Quadro 2 - Socioeducação nos PEEs dos Estados da Região Nordeste

\begin{tabular}{|c|c|c|c|}
\hline Estado & $\begin{array}{l}\text { Número da Lei do Plano Nacional de } \\
\text { Educação }\end{array}$ & $\begin{array}{l}\text { Meta sobre a } \\
\text { Socioeducação? }\end{array}$ & $\begin{array}{l}\text { Quantitativo de estratégia } \\
\text { referente à socioeducação }\end{array}$ \\
\hline Maranhão & Lei $n^{\circ} 10.099$, de 11 de junho de 2014 & Não & O6 estratégias \\
\hline Piauí & $\begin{array}{l}\text { Lei } n^{\circ} 6.733 \text {, de } 17 \text { de dezembro de } \\
2015\end{array}$ & Não & O3 estratégias \\
\hline Ceará & Lei $\mathrm{n}^{\circ} 16.025$, de 30 de maio de 2016 & Não & O1 estratégia \\
\hline $\begin{array}{l}\text { Rio Grande } \\
\text { do Norte }\end{array}$ & $\begin{array}{l}\text { Lei } n^{\circ} 10.049 \text {, de } 27 \text { de janeiro de } \\
2016\end{array}$ & Não & O1 estratégia \\
\hline Paraíba & $\begin{array}{l}\text { Lei } n^{\circ} 10.488 \text {, de } 23 \text { de junho de } \\
2015\end{array}$ & Não & O4 estratégias \\
\hline Pernambuco & Lei $n^{\circ} 15.533$, de 23 de junho de 2015 & Não & O5 estratégias \\
\hline Alagoas & Lei ${ }^{\circ} 7.793$, de 22 de janeiro de 2016 & Não & O1 estratégia \\
\hline Sergipe & $\begin{array}{l}\text { Lei } n^{\circ} 8.025 \text {, de } 04 \text { de setembro de } \\
2015\end{array}$ & Não & O1 estratégia \\
\hline Bahia & Lei $n^{\circ} 13.559$, de 11 de maio de 2016 & Não & 08 estratégias \\
\hline
\end{tabular}

Fonte: Elaboração própria (2019).

Na região Nordeste, cinco Estados apresentam planos estaduais com mais de três estratégias relativas à socioeducação (Maranhão, Piauí, Paraíba, Pernambuco e Bahia). No PEE do Maranhão, destaca-se a preocupação com a formação específica dos professores, agentes penais e com materiais pedagógicos específicos. Além disso, defende-se a garantia do acesso aos exames de certificação do ensino fundamental e médio.

No PEE do Piauí, ressalta-se a garantia do acesso à educação regular contemplando o que consigna o ECA e o SINASE. Já no PEE da Paraíba, observa-se estratégia que visa ao fortalecimento do acompanhamento e monitoramento do acesso e permanência, no ensino fundamental, dos jovens que cumprem medidas. Outra estratégia importante se refere à implantação da educação em direitos humanos em todos os níveis e modalidades de ensino e à inserção da educação em direitos humanos na formação inicial e continuada dos trabalhadores da educação, incluindo aqueles que atuam no sistema socioeducativo. No PEE do Estado de Pernambuco, destaca-se a preocupação com novas metodologias e tecnologias educacionais considerando as especificidades da educação nos espaços socioeducativos. 
Pretende ainda realizar, em parceria com as demais entidades federativas, censos específicos sobre a situação educacional das crianças e adolescentes em medidas. Outro aspecto de relevância diz respeito à oferta de cursos de formação inicial e continuada considerando o ECA, o SINASE, o CONANDA e a Declaração Universal dos Direitos Humanos.

Por fim, o PEE do Estado da Bahia propõe a integração dos dados do Censo Escolar da Educação Básica com o SINASE no âmbito da rede estadual e desenvolvimento de formas de oferta do ensino médio para atender jovens e adolescentes em instituições socioeducativas. Em complemento, pretende fortalecer os procedimentos de acesso à escola em tempo integral aos adolescentes e promover programas de formação inicial e continuada dos profissionais e de todos os atores que atuam no atendimento socioeducativo com vistas a aprofundar a compreensão sobre a aceitação das diferenças.

Quadro 3 - Socioeducação nos PEEs dos Estados da Região Centro-Oeste

\begin{tabular}{|c|c|c|c|}
\hline Estado & $\begin{array}{l}\text { Número da Lei do Plano Nacional de } \\
\text { Educação }\end{array}$ & $\begin{array}{l}\text { Meta sobre a } \\
\text { Socioeducação }\end{array}$ & $\begin{array}{l}\text { Quantitativo de } \\
\text { estratégias }\end{array}$ \\
\hline Distrito Federal & Lei ${ }^{\circ} 5.499$, de 14 de julho de 2015 . & Sim & 12 estratégias \\
\hline Goiás & Lei $n^{\circ} 18.969$, de 22 de julho de 2015 . & Não & O estratégias \\
\hline Mato Grosso & Lei $\mathrm{n}^{\circ} 10.111$, de 6 de junho de 2014 . & Não & O estratégias \\
\hline Mato Grosso do Sul & Lei ${ }^{\circ} 4.621$, de 22 de dezembro de 2014 . & Não & O1 estratégia \\
\hline
\end{tabular}

Fonte: Elaboração própria (2019).

Os PEEs dos Estados da região Centro-Oeste apresentam dois destaques importantes. O primeiro é a ausência de menção nos Planos Estaduais relacionada à política da Socioeducação nos Estados de Goiás e Mato Grosso. Os respectivos PEEs foram sancionados em 2015 e 2014. O segundo é o caso do Plano do Distrito Federal, sancionado em 2015, pois este se apresenta como o primeiro PEE que apresenta uma meta específica sobre a socioeducação. A meta 21 do referido plano enfatiza a garantia de 100\% do atendimento escolar para todos os adolescentes que cumprem medidas socioeducativas e internação cautelar em consonância com os princípios dos direitos humanos e com qualidade pedagógica.

A meta 21 apresenta 12 estratégias que visam, entre outras ações: implementar políticas de inclusão e permanência escolar para adolescentes e jovens que se encontrem cumprindo medidas socioeducativas em meio aberto, fechado e de internação cautelar; 
implementar proposta pedagógica específica para a socioeducação no Distrito Federal; articular e garantir, intersetorialmente, pelas secretarias com atuação nas áreas de criança, educação, assistência social, segurança pública, justiça, além do Ministério Público e da Vara da Infância e da Juventude, mecanismos de inserção, acompanhamento e atendimento à educação básica no ensino fundamental e médio de todos os adolescentes em cumprimento de medidas socioeducativas, em meio fechado e aberto. Outras estratégias que devem ser mencionadas se relacionam a criar condições para que todos os estudantes em cumprimento de medida socioeducativa tenham acesso à inclusão digital de forma pedagógica; garantir a oferta de educação profissional em cursos planejados de acordo com as características, as necessidades e os interesses dos adolescentes em cumprimento de medidas socioeducativas.

Quadro 4 - Socioeducação nos PEEs dos Estados da Região Sudeste

\begin{tabular}{|c|c|c|c|}
\hline Estado & $\begin{array}{l}\text { Número da Lei do Plano Nacional de } \\
\text { Educação }\end{array}$ & $\begin{array}{l}\text { Meta sobre a } \\
\text { Socioeducação }\end{array}$ & Quantitativo de estratégias \\
\hline Espírito Santo & Lei ${ }^{\circ} 10.382$, de 25 de junho de 2015 . & Não & O1 estratégia \\
\hline São Paulo & Lei $n^{\circ} 16.279$, de 8 de julho de 2016 & Não & 03 estratégias \\
\hline Rio de Janeiro & $\begin{array}{l}\text { Lei } n^{\circ} 5.597 \text {, de } 18 \text { de dezembro de } 2009 . \\
\text { Revisão do Plano em adequação às novas } \\
\text { diretrizes do PNE estão em discussão } \\
\text { Não sancionado }\end{array}$ & & \\
\hline Minas Gerais & Lei ${ }^{\circ} 2.197$, de 26 de dezembro de 2018. & Não & O1 estratégia \\
\hline
\end{tabular}

Fonte: Elaboração própria (2019).

Nos Planos Estaduais de Educação da Região Sudeste, observa-se que o Estado do Rio de Janeiro, até o momento, não sancionou seu PEE e apenas o Estado de São Paulo apresenta um PEE com três estratégias relacionadas à socioeducação. O conteúdo das estratégias objetiva implantar Salas de Atendimento Educacional Especializado (AEE) e fomentar a formação continuada dos profissionais da educação para o atendimento educacional especializado nas escolas urbanas, do campo, indígenas e de comunidades quilombolas e dos sistemas de cumprimento de medidas socioeducativas. Intenciona implementar políticas de inclusão e permanência na escola para adolescentes e jovens que se encontram em regime de liberdade assistida e em situação de rua. 
Quadro 5 - Socioeducação nos PEEs dos Estados da Região Sul

\begin{tabular}{|l|l|l|l|}
\hline Estado & $\begin{array}{l}\text { Número da Lei do Plano Nacional de } \\
\text { Educação }\end{array}$ & $\begin{array}{l}\text { Meta sobre a } \\
\text { Socioeducação }\end{array}$ & Quantitativo de estratégias \\
\hline Paraná & $\begin{array}{l}\text { Lei n }{ }^{\circ} 9.479, \text { de } 25 \text { de junho de } 2015 \text { de } \\
2015 .\end{array}$ & Não estratégias \\
\hline Santa Catarina & $\begin{array}{l}\text { Lei n } 16.794, \text { de } 14 \text { de dezembro de } \\
2015 . \text { Lei } n^{\circ} 16.794, \text { de } 14 \text { de dezembro } \\
\text { de } 2015 .\end{array}$ & Não & O2 estratégias \\
\hline $\begin{array}{l}\text { Rio Grande do } \\
\text { Sul }\end{array}$ & $\begin{array}{l}\text { Lei n }{ }^{\circ} 14.705, \text { de } 25 \text { de junho de } 2015 . \\
\text { Não }\end{array}$ & 01 estratégia \\
\hline
\end{tabular}

Fonte: Elaboração própria (2019).

Nos Planos Estaduais de Educação da Região Sul, apenas o Estado do Paraná possui mais de três estratégias. Observa-se que no Estado do Paraná, a socioeducação aparece em sete estratégias que pretendem: fomentar, em regime de colaboração entre Estado, União e Municípios, políticas de inclusão e permanência escolar para adolescentes que se encontram cumprindo medidas socioeducativas em meio aberto, fechado e internação cautelar; implementar proposta pedagógica específica para a socioeducação em consonância com os princípios do Sistema Nacional de Atendimento Socioeducativo (SINASE) e do Programa de Educação nas Unidades Socioeducativas do Paraná (Proeduse); articular, em regime de parceria, preferencialmente com instituições públicas, mecanismos de inserção e acompanhamento do atendimento à Educação Básica no Ensino Fundamental de adolescentes em cumprimento de medidas socioeducativas; assegurar equidade no atendimento escolar prestado aos adolescentes em cumprimento de medidas socioeducativas; e implementar mecanismos de acompanhamento escolar para adolescentes egressos de medidas socioeducativas.

Via de regra, os estados cujos PEEs apresentam menos de três estratégias em relação à socioeducação são estados que replicam a estratégia 7.24 do PNE, que trata da implementação de políticas de inclusão e permanência na escola para adolescentes e jovens que se encontram em regime de liberdade assistida e em situação de rua. Essa estratégia está relacionada à meta 07, referente ao fomento da qualidade da educação básica em todas as etapas e modalidades com vistas a atingir médias para o Índice de Desenvolvimento da Educação Básica (IDEB). 


\subsection{Reflexões decorrentes dos achados}

Os PEEs dos Estados das regiões Norte e Nordeste relacionam a socioeducação em metas diversificadas, que tratam desde o ensino fundamental a educação em direitos humanos até a formação e valorização dos profissionais da educação. Com isso, percebe-se uma relação mais estreita entre os PEEs dessas regiões e o que propõe o SINASE. Na região CentroOeste, o DF, além de ser a única entidade federativa que apresenta uma meta específica para a socioeducação, as estratégias descritas estão alinhadas com as diretrizes do SINASE. Ao passo que na região Sudeste, apesar de ser a região com maior número de jovens em unidades de internação socioeducativas (BRASIL, 2018), os PEEs são frágeis na consonância com os princípios do SINASE. Destaca-se da região Sul o Estado do Paraná com maior número de estratégias vinculadas tanto ao atendimento socioeducativo quanto à lei do SINASE, incluindo mecanismos de acompanhamento escolar para adolescentes egressos do sistema. Por outro lado, a socioeducação, em alguns PEEs, está vinculada ao sistema prisional e a jovens em situação de rua. Tal fato evidencia a perspectiva punitiva cuja herança histórica remonta ao Código de Menores de 1927 e à permanência dos fundamentos da doutrina da situação irregular, presentes no Código de Menores de 1979.

Esse dado revela a prevalência do atendimento escolar aos jovens do sistema socioeducativo na modalidade da EJA. Essa estreita e conflitante relação reproduz a organização do trabalho pedagógico do Sistema Prisional. Em outras palavras, mesmo com todos os avanços no campo legislativo, ainda existem fragilidades no que tange ao planejamento e execução de políticas de escolarização específicas para esses sujeitos.

Outro ponto que merece reflexão diz respeito ao fato de sete Estados replicarem a meta 7.24 do PNE, que se refere ao atendimento de jovens em liberdade assistida (medida de meio aberto). Importa considerar que o SINASE especifica as competências dos entes federativos em matéria de atendimento para a execução das medidas, ou seja, os estados replicam em seus planejamentos estratégias cuja ações são de competência municipal (liberdade assistida). Desse modo, tais PEEs não apresentam estratégias específicas de internação e semiliberdade que são de sua responsabilidade. Assim, demonstra uma inexistência de clareza no que tange às incumbências do pacto federativo instituído pelo SINASE. Essa ausência de clareza contribui para a dificuldade de se implementar intersetorialmente o atendimento socioeducativo?

Outra importante questão que deve ser problematizada é o fato de os PEEs dos Estados de Goiás e Mato Grosso não mencionarem estratégias relacionadas à socioeducação e de o Rio de Janeiro sequer ter sancionado seu plano. Segundo dados do Atlas da Violência (2019), a taxa 
nacional de homicídios de jovens, entre 15 a 29 anos, por grupo de 100 mil jovens, é de 69,9\%; enquanto os Estados do Goiás e Rio de janeiro apresentam taxa acima da nacional, de 91,6\% e 92,6\%, respectivamente. Já o Estado do Mato Grosso apresenta um índice de 54\%. Essas evidências retratam contradições no que tange ao tratamento das políticas públicas, sobretudo a política de educação, para a juventude em vulnerabilidade social desses Estados.

Em acréscimo à contradição referida anteriormente, ao cotejar os dados do Levantamento Anual do Sistema Nacional de Atendimento Socioeducativo (BRASIL, 2018), observa-se que este não faz menção à questão da escolarização dos adolescentes atendidos. Não indica quantos estão matriculados, não matriculados ou nível de escolarização dos jovens. Também não informa sobre a presença de Escolas/Núcleos de Ensino ou qualquer outro tipo de atendimento pedagógico que execute a política de escolarização no Estado. Ressalta-se, ainda, que em todo o documento do SINASE este evidencia o caráter pedagógico da medida socioeducativa em detrimento ao punitivo, mas o documento oficial que apresenta o panorama/acompanhamento/execução do atendimento socioeducativo do Brasil não considerou a escolarização como dado relevante a ser analisado/informado. Por isso, hoje não temos indicadores de como essa política está implementada na medida socioeducativa de internação.

Importa considerar que os direitos positivados hoje em lei, principalmente o direito à educação, impulsionador de políticas públicas para jovens em cumprimento de medida socioeducativa, são frutos de lutas dos movimentos e grupos sociais que se mobilizaram em prol da garantia dos direitos humanos de jovens infratores. Os direitos conquistados até o momento e positivados em lei, porém, não garantem a efetividade na prática, uma vez que

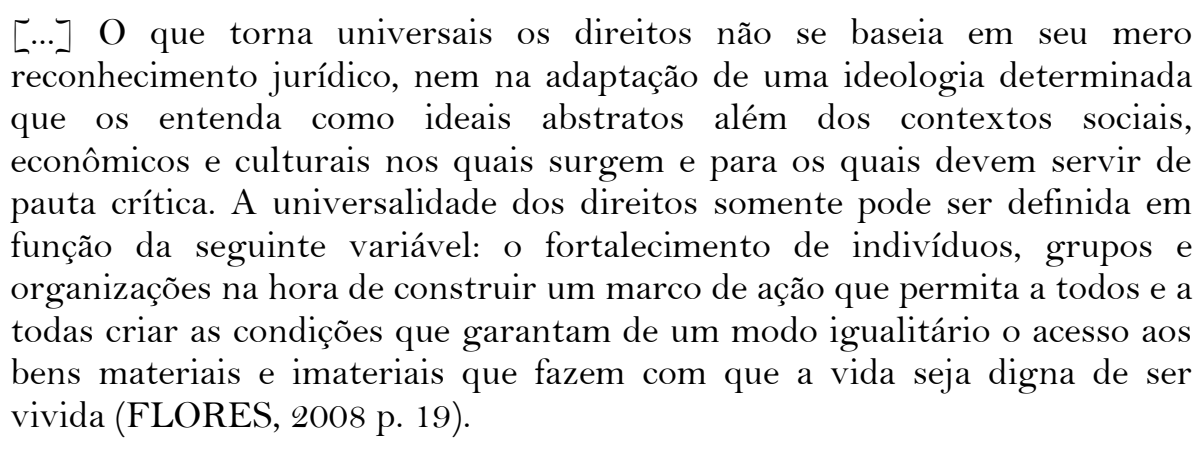

A dignidade da pessoa humana não é tema que cessa com a positivação de legislações. A mobilização pela defesa e efetivação de direitos sociais é uma luta constante, uma vez que pautas como a maioridade penal e a liberação de armas ganham força na conjuntura política atual. 


\section{Considerações finais}

Este artigo buscou descrever e identificar como a educação de jovens e adolescentes em cumprimento de medida socioeducativa está consignada nas metas e estratégias dos planos estaduais de educação das 27 unidades federativas. O panorama das metas e estratégias relacionadas à socioeducação, nos Planos Estaduais de Educação dos 26 Estados e do Distrito Federal, evidenciou que as regiões Norte e Nordeste apresentam o maior número de Estados, cujos PEEs incorporaram a escolarização dos socioeducandos na perspectiva do SINASE. Além disso, reafirmam a necessidade de formação em e para os Direitos Humanos, sugerindo maior diálogo entre o planejamento educacional e a política do SINASE.

De outro modo, outros PEES evidenciaram permanências com os Códigos de Menores de 1927 e 1969, uma vez que o PNE vincula a socioeducação aos menores em situação de rua e ao sistema prisional e sete Estados replicam as estratégias do PNE sem assumir a sua competência federativa, conforme assegura o SINASE.

Discutimos o direito à educação de jovens em cumprimento de medida socioeducativa, apresentando a positivação do direito à educação nos principais marcos normativos que orientam e regulam o Sistema Socioeducativo. Identificamos que, historicamente, esses adolescentes sofrem negligências pelos três Poderes (Executivo, Legislativo e Judiciário) no que se refere à elaboração, implementação e acompanhamento de políticas públicas de escolarização a jovens que cometem ato infracional.

Por fim, novas problemáticas se abrem a partir deste estudo. Entre elas: os Estados implementaram políticas específicas para a escolarização dos jovens socioeducandos, a partir da aprovação dos PEEs? Como se estrutura a política de escolarização da medida socioeducativa de internação nos Estados com o maior índice de violência? A prática de escolarização nas unidades socioeducativas, após aprovação do SINASE, rompe com a lógica punitiva historicamente instituída no Brasil? 


\section{Referências}

ACRE. Plano Estadual de Educação. Lei no 2.965, de 2 de julho de 2015. Aprova o Plano Estadual de Educação. Acre: Assembleia Legislativa do Estado do Acre, 2015. Disponível em: http://simec.mec.gov.br/sase/sase_mapas.php?uf=AC\&tipoinfo=1. Acesso em: 25 jun. 2019. https://doi.org/10.17648/fineduca-2236-5907-v9-89827

ALAGOAS. Plano Estadual de Educação. Lei $\mathrm{n}^{\circ}$ 7.795, de 22 de janeiro de 2016. Aprova o Plano Estadual de Educação. Alagoas: Assembleia Legislativa do Estado de Alagoas, 2016. Disponível em: http://simec.mec.gov.br/sase/sase_mapas.php?uf=AL\&tipoinfo=1. Acesso em: 25 jun. 2019. https://doi.org/10.20435/serie-estudos.v22i44.1049

AMAPÁ. Plano Estadual de Educação. Lei n ${ }^{\circ}$ 1.907, de 24 de junho de 2015. Aprova o Plano Estadual de Educação. Amapá: Assembleia Legislativa do Estado de Amapá, 2015. Disponível em: http://simec.mec.gov.br/sase/sase_mapas.php?uf=AP\&tipoinfo=1

Acesso em: 25 jun. 2019. https://doi.org/10.22409/movimento2000.v0io2.a20746

AMAZONAS. Plano Estadual de Educação. Lei ${ }^{\circ}$ 4.183, de 26 de junho de 2015. Aprova o Plano Estadual de Educação. Amazonas: Assembleia Legislativa do Estado do Amazonas, 2015. Disponível em: http://simec.mec.gov.br/sase/sase_mapas.php?uf=AM\&tipoinfo=1. Acesso em: 25 jun. 2019. https://doi.org/10.29280/rappge.v1i1.3707

ARONE, Mariângela. Sentidos e significados da escola para adolescentes em semiliberdade. Dissertação (Mestrado em Educação) - Pontifícia Universidade Católica de São Paulo, São Paulo, 2006. https://doi.org/10.5327/z1984-4840201623647

BAHIA. Plano Estadual de Educação. Lei 13.559, de 11 de maio de 2016. Aprova o Plano Estadual de Educação. Bahia: Assembleia Legislativa do Estado da Bahia, 2016. Disponível em: http://simec.mec.gov.br/sase/sase_mapas.php?uf=BA\&tipoinfo=1. Acesso em: 25 jun. 2019. https://doi.org/10.22278/2318-2660.2012.v36.n0.a642

BRASIL. [Constituição (1988)]. Constituição da República Federativa do Brasil de 1988. Brasília, DF: Presidência da República, [2016]. Disponível em: http://www.planalto.gov.br/ccivil_03/Constituicao/Constituiçao.htm. Acesso em: 25 jun. 2019. https://doi.org/10.11606/d.2.2010.tde-13122010-160747

BRASIL. Ministério da Educação. Diretrizes Nacionais para o Atendimento Escolar de Adolescentes e Jovens em Cumprimento de Medidas Socioeducativas. Parecer CNE/CEB $n^{\circ}$ 8/2015. Brasília: Ministério da Educação, 7 out. 2015. https://doi.org/10.14195/1647-

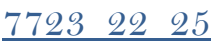

BRASIL. Lei 8.069, de 13 de julho de 1990. Dispõe sobre o Estatuto da Criança e do Adolescente e dá outras providências. Brasília: Casa Civil, [1990]. Disponível em: http://www.planalto.gov.br/ccivil_03/leis/18069.htm. Acesso em: 24 jul. 2019. https://doi.org/10.1590/0034-716719730005000016

BRASIL. Plano Nacional de Atendimento Socioeducativo: Diretrizes e Eixos operativos para o SINASE. Secretaria Especial dos Direitos Humanos. Brasília: CONANDA, 2013. 
BRASIL. Sistema Nacional de Atendimento Socioeducativo - SINASE/Secretaria Especial dos Direitos Humanos. Brasília, DF: CONANDA, 2006.

BRASIL. Lei 12.594, de 18 de janeiro de 2012. Institui o Sistema Nacional de Atendimento Socioeducativo, regulamenta a execução das medidas socioeducativos destinadas a adolescentes que pratique ato infracional. Brasília: Casa Civil, [2012]. Disponível em: http://www.planalto.gov.br/ccivil_03/_Ato2011-2014/2012/Lei/L12594.htm. Acesso em: 24 jul. 2019. https://doi.org/10.11606/d.22.2007.tde-08052007-174809

BRASIL. MINISTÉRIO DOS DIREITOS HUMANOS. Levantamento Anual SINASE 2016. Brasília: Ministério dos Direitos Humanos, 2018. https://doi.org/10.11606/t.2.2010.tde$\underline{26012011-151013}$

BRANCALHÃO, Walkíria R. D. A educação para o adolescente em conflito com a lei: mecanismo de inserção ou exclusão social. Dissertação (Mestrado em Educação) -Universidade Estadual Paulista, Marília, 2003.

CURY, Carlos Roberto Jamil. O Plano Nacional de Educação: duas formulações. Caderno de Pesquisa, n.104, p. 162-180, jul. 1998.

CEARÁ. Plano Estadual de Educação. Lei no 16.025, 30 de maio de 2016. Aprova o Plano Estadual de Educação. Ceará: Assembleia Legislativa do Estado do Ceará, 2016. Disponível em: http://simec.mec.gov.br/sase/sase_mapas.php?uf=CE\&tipoinfo=1. Acesso em: 25 jun. 2019. https://doi.org/10.1590/198053143720

DisTRITO FEDERAL. Plano Distrital de Educação. Lei no 5.499, de 14 de julho de 2015. Aprova o Plano Distrital de Educação. Distrito Federal: Poder Executivo, 2015. Disponível em: http://simec.mec.gov.br/sase/sase_mapas.php? uf=DF \&tipoinfo=1. Acesso em: 25 jun. 2019. https://doi.org/10.18366/conae.2015.0001

ESPÍRITO SANTO. Plano Estadual de Educação. Aprova o Plano Estadual de Educação. Lei 10.382, de 25 de junho de 2015. Espírito Santo: Assembleia Legislativa do Estado do Espírito Santo, 2015. Disponível em: http://simec.mec.gov.br/sase/sase_mapas.php?uf=ES\&tipoinfo=1

Acesso em: 25 jun. 2019. https://doi.org/10.5753/ersirj.2018.4663

FLORES, Joaquín Herrera. La reinvención de los derechos humanos. Andalucia: Atrapasueños, 2008.

GOIÁs. Plano Estadual de Educação. Lei no 18.969, de 22 de julho de 2015. Aprova o Plano Estadual de Educação. Goiás: Assembleia Legislativa do Estado do Goiás, 2015. Disponível em: http://simec.mec.gov.br/sase/sase_mapas.php? uf=GO\&tipoinfo=1. Acesso em: 25 jun. 2019. https://doi.org/10.14295/2596-2221.xviceel.2018.272

HORTA, José Silvério Bahia. Liberalismo, Tecnocracia e Planejamento Educacional no Brasil. São Paulo: Cortez, 1982.

IPEA - Instituto de Pesquisa Econômica Aplicada; FBSP - Fórum Brasileiro de Segurança Pública (Org.). Atlas da Violência. Brasília: Rio de Janeiro: São Paulo: Instituto de Pesquisa Econômica Aplicada; Fórum Brasileiro de Segurança Pública, 2019. https://doi.org/10.17013/risti.23.103-118 
LACÉ, Andréia Mello; SCHERRE, Paula; SOUZA, Lívia Silva. O percurso tensionado do Plano Nacional de Educação: da elaboração à sanção. In: SIMPÓSIO DE EDUCAÇÃO: COTIDIANO, HISTÓRIA E POLÍTICAS, 2., 2016, Rio de Janeiro. Anais [...]. Rio de Janeiro: UGB/RJ, 2016, p. 217-237. Disponível em: http://www.educacaolibertaria.com.br/site/anais2/16\%20O\%20PERCURSO\%20TENSIO NADO\%20DO\%20PLANO\%20DISTRITAL\%20DE\%20EDUCA\%C3\%87\%C3\%83O.pdf. Acesso em: 28 jun. 2019. https://doi.org/10.5151/despro-sbds15-1st703a

MATO GROSSO. Plano Estadual de Educação. Lei n ${ }^{\circ}$ 10.111, de 6 de junho de 2014. Aprova o Plano Estadual de Educação. Mato Grosso: Assembleia Legislativa do Estado do Mato Grosso, 2014. Disponível em: http://simec.mec.gov.br/sase/sase_mapas.php?uf=MT\&tipoinfo=1

Acesso em: 25 jun. 2019. https://doi.org/10.20435/serie-estudos.v22i44.1049

MATO GROSSO DO SUL. Plano Estadual de Educação. Lei no 4.621, de 22 de dezembro de 2014. Aprova o Plano Estadual de Educação. Mato Grosso do Sul: Assembleia Legislativa do Estado do Mato Grosso do Sul, 2014. Disponível em: http://simec.mec.gov.br/sase/sase_mapas.php?uf=MS\&tipoinfo=1

Acesso em: 25 jun. 2019. https://doi.org/10.20435/serie-estudos.v22i44.1049

MARANHÃO. Plano Estadual de Educação. Lei n ${ }^{\circ}$ 10.099, de 11 de junho de 2014. Aprova o Plano Estadual de Educação. Maranhão: Assembleia Legislativa do Estado do Maranhão, 2014. Disponível em: http://simec.mec.gov.br/sase/sase_mapas.php?uf=MA\&tipoinfo=1 Acesso em: 25 jun. 2019. https://doi.org/10.18677/agrarian_academy_2016b18

MINAS GERAIS. Plano Estadual de Educação. Lei n 23.197, de 26 de dezembro de 2018. Aprova o Plano Estadual de Educação. Minas Gerais: Assembleia Legislativa do Estado de Minas Gerais, 2018.2 Disponível em: http://simec.mec.gov.br/sase/sase_mapas.php?uf=MG\&tipoinfo=1

Acesso em: 25 jun. 2019. https://doi.org/10.14295/2596-2221.xviceel.2018.262

NERI, Natasha Elbas. "Tirando a cadeia dimenor": a experiência da internação e as narrativas de jovens em conflito com a lei no Rio de Janeiro. Universidade Federal do Rio de Janeiro IFCS, 2009. https://doi.org/10.5753/ersirj.2018.4649

PARÁ. Plano Estadual de Educação. Lei no 8.186, 23 de junho de 2015. Aprova o Plano Estadual de Educação. Pará: Assembleia Legislativa do Estado do Pará, 2015. Disponível: http://simec.mec.gov.br/sase/sase_mapas.php?uf=PA\&tipoinfo=1. Acesso em: 25 jun. 2019. https://doi.org/10.17771/pucrio.acad.16671

PARANÁ. Plano Estadual de Educação. Lei no 9.479, de 25 de junho de 2015 de 2015. Aprova o Plano Estadual de Educação. Paraná: Assembleia Legislativa do Estado do Paraná, 2015. Disponível em: http://simec.mec.gov.br/sase/sase_mapas.php?uf=PR\&tipoinfo=1. Acesso em: 25 jun. 2019. https://doi.org/10.4025/imagenseduc.v9i1.44262

PARAÍ́BA. Plano Estadual de Educação. Lei no 10. 488, 23 de junho de 2015. Aprova o Plano Estadual de Educação. Paraíba: Assembleia Legislativa do Estado da Paraíba, 2015. Disponível em: http://simec.mec.gov.br/sase/sase_mapas.php?uf=PB\&tipoinfo=1. Acesso em 25 jun. 2019. https://doi.org/10.22478/ufpb.2359-7003.2019v28n1.42301 
PERNAMBUCO. Plano Estadual de Educação. Lei n ${ }^{\circ}$ 15.533, de 23 de junho de 2015. Aprova o Plano Estadual de Educação. Pernambuco: Assembleia Legislativa do Estado de Pernambuco, $2015 . \quad$ Disponível em: http://simec.mec.gov.br/sase/sase_mapas.php?uf=PE\&tipoinfo=1. Acesso em: 25 jun. 2019. https://doi.org/10.5327/z1519-1672201400650003

PEREIRA, Irandi. O adolescente em conflito com a lei e o direito à educação. Tese (Doutorado em Educação) - Universidade de São Paulo, São Paulo, 2006. https://doi.org/10.11606/t.42.2019.tde-12042018-141555

PIAUÍ. Plano Estadual de Educação. Lei $n^{\circ}$ 6.733, de 17 de dezembro de 2015. Aprova o Plano Estadual de Educação. Piauí: Assembleia Legislativa do Estado de Piauí, 2015. Disponível em: http://simec.mec.gov.br/sase/sase_mapas.php?uf=PI\&tipoinfo=1. Acesso em: 25 jun. 2019. https://doi.org/10.11606/t.48.2019.tde-14052019-123037

SARAIVA, Liliane G. Medidas sócio-educativas e a escola: uma experiência de inclusão. Dissertação (Mestrado em Educação) - UNIJUUí, Ijuí, 2006.

SAVIANI, Dermeval. Sistema Nacional de Educação e Plano Nacional de Educação: significados, controvérsias e perspectivas. Campinas: Autores Associados, 2014. https://doi.org/10.15628/rbept.2019.8218

SILVA, Enid Rocha Andrade da; OLIVEIRA, Raissa Menezes. $O$ adolescente em conflito com a lei e o debate sobre a redução da maioridade penal: esclarecimentos necessários. Nota Técnica número 20. Brasília: IPEA, 2015.

SPOSITO Marilia Pontes (Coord.). Estado da Arte sobre juventude na pós-graduação brasileira: educação, ciências sociais e serviço social (1999-2006). Belo Horizonte: Argvmentvm, 2009. v. 1.

RIO GRANDE DO NORTE. Plano Estadual de Educação. Lei n ${ }^{\circ}$ 10.049, 27 de janeiro de 2016. Aprova o Plano Estadual de Educação. Rio Grande do Norte: Assembleia Legislativa do Estado do Rio Grande do Norte, 2016. Disponível em: http://simec.mec.gov.br/sase/sase_mapas.php?uf=RN\&tipoinfo=1. Acesso em: 25 jun. 2019. https://doi.org/10.24873/j.rpemd.2019.05.446

RIO GRANDE DO SUL. Plano Estadual de Educação. Lei n 14.705, de 25 de junho de 2015. Aprova o Plano Estadual de Educação. Rio Grande do Sul: Assembleia Legislativa do Estado do Rio Grande do Sul, 2016. Disponível em: http://simec.mec.gov.br/sase/sase_mapas.php?uf=RS\&tipoinfo=1. Acesso em: 25 jun. 2019. https://doi.org/10.36576/summa.14089

RONDÔNIA. Plano Estadual de Educação. Lei no 3.565, de 3 de junho de 2015. Aprova o Plano Estadual de Educação. Rondônia: Assembleia Legislativa do Estado de Rondônia, 2015. Disponível em: http://simec.mec.gov.br/sase/sase_mapas.php?uf=RO\&tipoinfo=1. Acesso em: 25 jun. 2019. https://doi.org/10.17143/ciaed/xxiilciaed.2017.00235

RORAIMA. Plano Estadual de Educação. Lei $\mathrm{n}^{\circ}$ 1.008, 3 de setembro de 2015. Roraima: Assembleia Legislativa do Estado de Roraima, 2015. Disponível em: http://simec.mec.gov.br/sase/sase_mapas.php?uf=RR\&tipoinfo=1. Acesso em: 25 jun. 2019. https://doi.org/10.18227/2237-8057rarr.v6i3.4059 
SANTA CATARINA. Plano Estadual de Educação. Lei no 16.794, de 14 de dezembro de 2015. Aprova o Plano Estadual de Educação. Santa Catarina: Assembleia Legislativa do Estado de Santa Catarina, 2015. Disponível em: http://simec.mec.gov.br/sase/sase_mapas.php?uf=SC\&tipoinfo=1. Acesso em: 25 jun. 2019. https://doi.org/10.14393/19834071.2016.32970

SÃO PAULO. Plano Estadual de Educação. Lei $n^{\circ}$ 16.279, de 8 de julho de 2016. Aprova o Plano Estadual de Educação. São Paulo: Assembleia Legislativa do Estado de São Paulo, 2016. Disponível em: http://simec.mec.gov.br/sase/sase_mapas.php?uf=SP\&tipoinfo=1

Acesso em: 25 jun. 2019. https://doi.org/10.29381/0103-8559/2019290143-5

SERGIPE. Plano Estadual de Educação. Lei no 8.025, de 04 de setembro de 2015. Aprova o Plano Estadual de Educação. Sergipe: Assembleia Legislativa do Estado de Sergipe, 2015. Disponível em: http://simec.mec.gov.br/sase/sase_mapas.php?uf=SE\&tipoinfo=1

Acesso em: 25 jun. 2019. https://doi.org/10.14295/remea.v35i1.7510

TOCANTINS. Plano Estadual de Educação. Lei no 2.977, de 08 de julho de 2015. Tocantins: Assembleia Legislativa do Estado de Tocantins, 2015. Disponível em: http://simec.mec.gov.br/sase/sase_mapas.php?uf=TO\&tipoinfo=1

Acesso em: 25 jun. 2019. https://doi.org/10.11606/t.12.2018.tde-06122018-101225 